important factor in causing intellectual changes.

The rationale behind the training experiment is simple. You think that social interaction is important, so you give a child a pre-test on some important cognitive skill like Piaget's conservation test, then give them a training period, and then a post-test exactly like the pre-test. If they are better on the post-test than a control group, you conclude that social interaction normally causes the development in question.

There are two difficulties, neither solved by Perret-Clermont. The first is that these positive results might be quite artificial. Many other people have done successful conservation training experiments using quite different methods. There must be at least a dozen successful ways, most of which do not involve social interaction between children. There is no way of knowing which has isolated the real cause.

Secondly, it's peculiarly difficult to get the controls right. For example we cannot say from Perret-Clermont's data whether it is social interaction with anyone or social interaction with children that is important. She does not take her effects apart. Nevertheless her work is simple and ingenious, and she presents an attractive causal hypothesis. But how are we ever to test it properly?

P.E. Bryant is Watts Professor of Psychology at the University of Oxford.

\section{Vesicle in a basket}

\section{Ernst Ungewickell}

Coated Vesicles. Edited by C.D. Ockleford and A. Whyte. Pp.344. (Cambridge University Press: 1980 .) $£ 40, \$ 90$.

FOR more than 10 years, up to about 1975 , the study of coated vesicles was almost exclusively the province of morphologists who early on had recognized the importance of these organelles in exo- and endocytotic processes. This state of affairs changed dramatically when $B$. Pearse succeeded in isolating pure vesicles in quantity, and thus made them available to biochemists. It is this latter group who will profit most from this monograph.

The volume contains contributions by representatives of a number of specialized fields, most of whom offer stimulating discussions and speculations on what are often rather fragmentary data. The 12 chapters fall into three groups: an introductory survey of the field; exploration of specific functions of the vesicles; and discussions of models aimed at describing endocytotic events at a molecular level.

The book opens with a classification of endocytotic processes, and an evaluation of the role of coated vesicles in micropinocytosis and their comparison structurally and functionally with smoothwalled micropinocytotic vesicles. This is followed by a summary of the occurrence of coated vesicles in different species and cell types, and a discussion of the different pathways of intracellular transport.

The logical sequence of the contributions proceeds with a consideration of the coated vesicle in plant cells. Subsequent chapters describe in detail the involvement of coated vesicles in IgG transmission, their role in membrane retrieval in neurosecretory cells, and their function in vitellogenesis and secretory processes. All of these reviews are supplemented with high-quality electron micrographs showing the characteristic appearance of coated vesicles from different sources in both median and tangential sections.

Molecular aspects of receptor-mediated transport are discussed next, and models proposed by various researchers are compared. The authors of this contribution conclude that specific protein transport is too complex a process to be described by any one of the proposed models. It is my impression that the same might be said of the models which try to explain how membranes invaginate to assume the configuration of coated vesicles, a topic which is also discussed. In the penultimate chapter, structural aspects of coated vesicles are reviewed; this reveals that surprisingly little work has been done on the structure of the major coat protein, clathrin. The book concludes with a cautious discussion of the importance of coated vesicles in medical science.

In summary, the book provides comprehensive coverage of the knowledge of coated vesicles up to the end of 1978 (a list of more recent publications appears in an appendix) and clearly indicates directions for future research. I recommend it to anyone who is new to the field or who is considering working with coated vesicles.

Ernst Ungewickell is at the Biological Laboratories, Harvard University.

\title{
Much to ponder in lipid evolution
}

\section{T.W. Goodwin}

Lipids in Evolution. By William R. Nes and

W. David Nes. Pp.195. (Plenum: 1980.) $\$ 29.50, £ 18.59$.

THE authors of this book, père et fils, are clearly fascinated by the problem of relating biochemical parameters to the classical ideas on evolution. Concentrating on lipids, they have sifted through a great amount of information and bravely attempted to discern clear evolutionary patterns. A perusal of their final chapter indicates how difficult this data analysis was and how few new correlations have emerged. In almost every aspect studied, facts crop up which invalidate an emerging generalization. Indeed the authors' occasional frustrations are revealed by such comments as "The situation is made worse by the phylum Mollusca". This follows the view that as arthropods cannot synthesize sterols it would be reasonable to assume that molluscs, which from fossil records pre-date arthropods, would also not synthesize sterols; alas, "biosynthesis of sterols is a common property of molluscs".

The first four main chapters deal succinctly with dating and chronology, the palaeontological record, the origin of oxygen, and the temperature and $p \mathrm{H}$ problem. It is clear from the chapter on oxygen that anaerobic organisms can make some unsaturated fatty acids and isoprenoids anaerobically from acetylCoA. A discussion of how anaerobic organisms make acetyl-CoA would have been most welcome, as would some comment on the quantitative aspects of acetyl-CoA, lipid and isoprenoid production in the presence and absence of oxygen in organisms such as yeast.

"Phylogenetics and Occurrence", the next chapter, is a straightforward and thorough account of lipid and sterol distribution in nature. The main conclusion is that no lipid distribution is unique to prokaryotes or to eukaryotes, and this is emphasized by the observation that the fatty acid pattern in blue-green bacteria (algae) is much closer to that of the eukaryote algae than to that of the photosynthetic bacteria.

The authors next turn to a consideration of phylogenetics and biosynthesis, paying particular attention to the important bifurcation in sterol synthesis at the point of cyclization of squalene 2,3-oxide. This clearly separates non-photosynthetic from photosynthetic organisms. In the former, the first cyclization product is lanosterol, whereas in the latter it is cycloartenol. The reason for this bifurcation is still obscure.

This is a book packed with interesting information and spiced with enjoyable speculation. It will help to broaden the outlook of conventional natural-product chemists and will give biologists much to ponder over.

T.W. Goodwin is Johnston Professor of Biochemistry at the University of Liverpool. 